\title{
CONSEQUENCES OF THE HIGH ABUNDANCE OF BOMBUS TERRESTRIS ON THE POLLINATION OF VICIA FABA
}

\author{
Smith-Ramírez C. * 1, 2,3, Rendón-Funes A. ${ }^{1,2,4}$, Barahona-Segovia R.M. ${ }^{1}$, Moya W. ${ }^{5}$ \\ 'Dpto. De Ciencias Biológicas y Biodiversidad, Universidad de Los Lagos, 1305 Av. Füchslocher, Osorno, Chile. \\ ${ }^{2}$ Instituto de Ecología y Biodiversidad-Chile (IEB), Las Palmeras 3425, Santiago, Chile. \\ 3 Instituto de Conservación, Biodiversidad y Territorio, Facultad de Ciencias Forestales, Universidad Austral de Chile, Isla \\ Teja s/n, Valdivia, Chile. \\ ${ }^{4}$ Área de Ecología, Museo de Historia Natural Alcide d'Orbigny, 1458 Av. Potosí, Cochabamba, Bolivia. \\ ${ }^{5}$ Laboratorio de Ecología, Departamento de Ciencias Biológicas \& Biodiversidad, Universidad de los Lagos, campus \\ Osorno, Osorno, Chile
}

Journal of Pollination Ecology, 29(20), 2021, pp 258-272

DOI: $10.26786 / 1920-$

$7603(2021) 630$

Received 10 March 2020, accepted 26 August 2021 *Corresponding author: cecilia.smith@ulagos.cl

\begin{abstract}
One of the main visitors to Fabia bean crops (Vicia faba) in South America is the invasive bumblebee species Bombus terrestris. This is particularly true in Chile, where B. terrestris was first introduced in 1997 and is now common over much of the country. In this study, we evaluated the activity of the principal pollinators of $\mathrm{V}$. faba over two cropping seasons by assessing their visitation rates while distinguishing between legitimate visits, likely to lead to pollination, and nectar robbery. We then determined the net contribution of insect visitation on pod and seed set. We recorded seven species of floral visitors. Most visits (legitimate visits and robbery) were from the honeybee (Apis mellifera), with $B$. terrestris being the next most common visitor. In the case of B. terrestris, $87.19 \%$ of visits were nectar robbery. On average, the same flower perforation was visited 23 times by B. terrestris during the flower's lifespan. In general, the frequency of legitimate visits varied with pollinator identity and year. For B. terrestris, each flower received an average of 0.95 legitimate visits during its entire lifespan. The time spent by B. terrestris visiting flowers for both nectar robbery or pollen collection decreased after the first day of flowering suggesting resource depletion. The number of pods, total seed number, and seed weight were lower where self rather than open pollination. This suggests that open pollination increased reproductive success. We conclude that $B$. terrestris was likely to contribute relatively little to pollination while at the same time depleting floral resources throughout the flowers' lifespan. Bombus terrestris is likely to make $V$. faba flowers less attractive to other more effective pollinators. As a result, this may potentially drive interspecific competition for pollen and nectar within the crop.
\end{abstract}

Keywords-Apis mellifera, Bombus dahlbomii, Bombus ruderatus, Bombus terrestris, Cadeguala, nectar robbery

\section{INTRODUCTION}

Vicia faba (broad bean, faba) an important crop worldwide, with the main producers being China, Ethiopia and Egypt (FAO 2015). The annual world production is estimated to be approximately 200,000 tonnes (Ansoleaga \& Salinas 2010). The seeds of this crop are rich in proteins and the plant is easily adaptable to different environmental conditions (Crepon et al. 2010). While the flower of this legume is partially self-pollinated, pod and seed production still benefit from insect crosspollination (Suso \& Maalouf 2009; Marzinzig et al. 2018). The dependency of $V$. faba on insect pollinators ranges from 4 to $84 \%$ (Aouar-sadil et al. 2008; Bommarco et al. 2012; Cunningham \& Le Feuvre 2013; Bishop et al. 2016; Bond \& Poulsen 1983; Suso et al. 2001), although (Bartomeus et al. 2014; Free 1966; Nayak et al. 2015) reported yield increases from 40 to $185 \%$ when pollinated by insects. Pollinators also promote self-pollination by stimulating the release of an exudate from the 
stigmas which promotes pollen germination (Bond \& Poulsen 1983). Typically, pollinators of $V$. faba will provide useful cross-pollination up until a threshold beyond which increased pollinator abundance results in no increase in yield (Suso et al. 2001).

Worldwide, bumblebees (Bombus spp.) and honeybees (Apis mellifera) are the main pollinators of $V$. faba (Kendall \& Smith 1975; Marzinzig et al. 2018), although other pollinators include the bees Xylocopa spp., Eucera spp. (Aouar-sadil et al. 2008) as well as sweat bees (Halictidae) and cuckoo bees (Nomadinae) (Poulsen 1973; Kendall \& Smith 1975; Tasei 1976; Marzinzig et al. 2018). Marzinzig et al. (2018) showed that cross-pollination of $V$. faba is mainly the result of long-tongued species, such as $B$. hortorum, although others have identified $A$. mellifera to be another important pollinator (Kyllönen 2018). Not all visitations by bees are legitimate, entering directly through the main opening of the flower and having at least the potential to lead to a seed set. For example, $B$. terrestris commonly robs nectar from flowers by biting holes at the base. This behaviour avoids the plant stigmas while still removing nectar (Aouarsadli et al. 2008). Apis mellifera is also a secondary nectar robber that makes use of these holes already created by B. terrestris (Marzinzig et al. 2018).

Unlike the often-diverse faunas of bumblebees encountered in Europe, Southern South America has only one native long-tongued bumblebee, $B$. dahlbomii. The populations of this native species have declined substantially after the arrival of $B$. terrestris, with similar trends observed in both Argentina and Chile (Arbertman et al. 2006; SmithRamírez et al. 2014). The invasion of B. terrestris, native to Europe, has largely been a result of the importation of commercially produced colonies used to promote pollination in several economically important crops (Aizen et al. 2018; Naeem et al. 2018). It has been shown that this trade is responsible for $B$. terrestris being invasive in many areas of the world (Kenis et al. 2008). In Chile, B. terrestris was introduced in 1997 and since then has quickly become naturalised so that it is now overabundant (sensu Lunney et al. 2007) and widespread across the temperate zones of Chile and Argentina (Sáez et al. 2014; Aizen et al. 2018).

Although nectar robbery is common in $V$. faba flowers and has previously been suggested not to be detrimental to yields (Newton \& Hill 1983), it can still have a negative effect by promoting less efficient self-pollination (Kendall \& Smith 1975; Marzinzig 2018). Where high enough abundances of $B$. terrestris occur, the probability that some of them make legitimate visits facilitating successful pollination may indeed be the case. However, this is only likely to be the case where nectar is not a limiting resource. Where nectar production is limited, B. terrestris could be robbing this resource from flowers that would otherwise be selfpollinated or pollinated by other species over the flower's lifespan. As flowers' attractiveness to pollinators depends on there being sufficient pollen and nectar, resource depletion by robing $B$. terrestris might negatively affect legitimate flower visitations and lead to reduced yields (Sáez et al. 2017). Assessing this effect can be challenging, although time spent by insects gathering these resources has been used as a proxy to indicate whether nectar and pollen are limited (Hingston \& McQuillan 1999). In addition to direct resource depletion in flowers, repeated visits by one pollinator (or robber) might damage the flower, as shown for raspberries (Sáez et al. 2017).

Here we study whether changes in abundance (as visit rate to flowers) of $B$. terrestris can affect the overall rates of $V$. faba visits from other pollinator species during the lifetime of a flower. We focused on assessing inter-specific competition for pollen and nectar resources to identify how this affects the pollination of $V$. faba. We assessed this effect over two years to account for interannual abundance variation in B. terrestris (Ramires 2019). Our specific objectives were: 1) To identify the percentage of flowers visited by pollinator species and the rates at which legitimate and robbery visits occurred; 2) To test if there was a correlation between the number of legitimate visits and robbery events during the life of the flowers; 3 ) To evaluate whether the time spent in legitimate and robbery visits differ over the flowers lifespan; 4) To assess interannual variation in each of the aforementioned parameters, and finally; 5) To quantify the extent of pollinator dependence for a $V$. faba cultivar commonly used in south-central Chile. 


\section{MATERIALS AND METHODS}

\section{STUDY AREA}

We studied $V$. faba L. subsp. faba var. major cultivar "agua dulce" plants in a small field (0.4 hectares) located at $40.76^{\circ} 99.5^{\prime}(\mathrm{S}), 73.20^{\circ} 10.9^{\prime}(\mathrm{W})$, approximately $1.5 \mathrm{~km}$ from Río Negro, in Osorno Province, Chile. In the field, an area of $1200 \mathrm{~m}^{2}$ was planted with $V$. faba, with no insecticide applied to the crop. Other crops were also grown in the field, including other beans and peas, raspberries and some fruit trees attractive to pollinators. Native plants, such as blackberries, as well as ornamental plants attractive to pollinators, were also found within 2 to $10 \mathrm{~m}$ of the field margins. The landscape matrix surrounding the field was dominated by managed grasslands. As B. terrestris shows population fluctuations following a second order curve, it is common for the annual abundances to be highly variable (Smith-Ramirez et al. 2014). For this reason, we ran this study over two years (2018 and 2019). The average temperature during the flowering season of $V$. faba was $17.8^{\circ} \mathrm{C}$ in 2018 and $15.3^{\circ} \mathrm{C}$ in 2019 . Average precipitation accumulated over the flowering period was respectively $17.8 \mathrm{~mm}$ and $14.1 \mathrm{~mm}$ in 2018 and 2019. These climate data were collected from the nearest meteorological station, "Cañal Bajo" (https://climatologia.meteochile.gob.cl).

\section{SAMPLE FIELD}

Vicia faba was sown in late August (austral winter) in the first year and in late September in the second year. Seeds used to establish the crop were purchased in the local market for 2018, while seeds harvested in the first year were then used to establish the crop grown in 2019. We delayed the sowing in the second year because of the rainy condition during that winter. No managed colonies of $B$. terrestris or $A$. mellifera were located within a radius of ca. $3 \mathrm{~km}$ of the studied garden. Observations of pollinator visitation rates, their behaviour, and their effect on seed sets were undertaken from the last weeks of November until the first week of December in both years. All seeds from the crop were harvested in January of the following year. To evaluate species pollinator diversity and their behaviour (legitimate and robbery visits), we conducted two types of observations, one with cameras and another one with observers in the field. Although cameras can provide the necessary information, their static focus limits their range, and so it was considered important to include observers to complement and better assess the variation and behaviour of pollinators on this crop.

It was important to distinguish what day legitimate visits first occurred, as $V$. faba flowers cannot be fertilized during the first day of their onset (Stoddard 1986). We considered legitimate pollination to have occurred when the keel (the modified petals that cover the flower's reproductive organs) was lowered by an insect placing its head and thorax over the anthers and stigma. When the insect stands on the keel petals, they are lowered by the first pair of legs and expose the anthers for pollen collection (we call this behaviour Downing the Keel=DK). In some rare legitimate visits, the insect did not push the keel sufficiently and flew away without collecting pollen (we refer to this behaviour as Non-Downing of the Keel =NDK). Due to the angle of the camera when viewing the flowers, or because of the insect physically obscuring reproductive parts of the flower, it was not always possible to distinguish between these two behaviours (NV). Robbing behaviour was recorded when the insect inserted its proboscides in the perforation at the base of the flower. We consider this behaviour in more detail below.

Camera method: We used four Brinno TLC200 Time Lapse cameras, with images recorded every second for two to five consecutive days, using a configuration of FPS: 5-20 fps and a shooting interval of $1 \mathrm{sec}$. The cameras were active between 07:00 - 21:00 hrs. Each camera was placed facing one plant, with one to three inflorescences with open flowers. The total observation time for the first year was $155.93 \mathrm{hrs}$ and $334.70 \mathrm{hrs}$ for the second year. We standardized legitimate visits and nectar robbery per flower, using the number of studied flowers recorded per camera during anthesis. The standardization per hour was made individually for each flower, reflecting that they opened at different times (Fig. 1A). Each flower bud takes around 30 minutes to open completely; we considered it open when the largest petal (the banner) starts to move.

We recorded two plants with a total of 27 buds and/or flowers during the first year and two plants with 37 buds and/or flowers during the second 
year. We recorded the species that visited the flower, the type of visit made (legitimate, DK/NDK, NV or robbery), the exact time the pollinator appeared, the number of visits made and the number of flowers visited. We identified each bud and/or flower during the recordings and counted their visits separately. In addition, the cameras were used to record the visits of pollinators in a sample of 10 flowers (out of 27) for the first year and 13 flowers (out of 37) for the second year. These 23 flowers were chosen because the cameras recorded pollinator visits over the entire flowers' lifespan. For these cases, we recorded the daily visits of pollinators, as well as their behaviour up until a day after the last time the flowers were open. When we observed that a flower was closed for an entire day, we assumed that the flower had senescent the day before.

To estimate the available resource in nectar and pollen, we recorded the time spend by A. mellifera, in legitimate visits for each day during the flowering period (42 visits on day one, 32 visits on day two, and 38 visits on day three). On the first day, we only considered the visits that occurred after one or two hours following the flower opening (to give the time for pollen to dry). It was not possible to make this comparison for $B$. terrestris as the number of legitimate visits was too few by day 3 to be viable for robust statistical analysis. For 27 legitimate visits per day, and for the two main pollinator species, we recorded DK or NDK behaviour (total $N=162$ visits), including the time spend undertaking each behaviour. We recorded the time spend undertaking robbery between $17: 49$ and $19: 58$ by $A$. mellifera and $B$. terrestris in a sample of 175 visits (day one), 224 visits (day two) and 104 visits (day three) for both years. We used this period because it corresponds to high nectar robbing activity for both main visitors probably related with nectar secretion.

On-site observer: Three people observed the activity of pollinators simultaneously over periods of 10 minutes (130 min in year one and $140 \mathrm{~min}$ in year two) on the flowers of 10 plants chosen randomly and located within a plot of around $2 x$ $2 \mathrm{~m}^{2}$. Over two years, each 10-minute observation was made between 10:10 to 15:10 over three nonconsecutive days. While in the first year, the flowers opened from around $10 \mathrm{am}$, early openings were unusual in the second year. As such, we started our observations at 12:00 hrs. We chose this observation time because $V$. faba replenishes its nectar level overnigh (Stoddard \& Bond 1986). We would therefore expect an increase of robbery on nearby adult flowers in the morning and the afternoon. For each observation (observer and camera), we counted the total number of open flowers per plant to standardize the observations. For both methods, we recorded the same information, except for the time (seconds) spent in legitimate visits, nectar robbery and where the flower keel was moved (this only being documented from the camera data). We also monitored the activity of 12 randomly chosen individuals of $A$. mellifera and $B$. terrestris to document the frequency of change in their foraging behaviour. From these individuals, we recorded how many times they changed from legitimate visits to robbery by the next day for the same visited flower. We did not see any activity in extra-floral nectaries of $V$. faba.

Pollination and reproduction of $V$. faba: In order to measure the contribution of pollinators to the reproductive output of $V$. faba, we conducted hand-pollination experiments of self-pollination, artificial cross-pollination and open pollination in each year of our study. In both years, we selfpollinated three or four flowers per plant for 30 plants (118 flowers in total), as well as manually cross-pollinating one to three flowers per plant for another 52 plants. Once hand-pollination was undertaken, we covered the treated buds with bags to prevent legitimate visits and robbery. As a control, we also marked 90 flowers over 60 plants to study open pollination. Some of the plants in which we did the different treatments were the same. We lost part of the production of the crosspollination experiment due to an unknown reason in the first year and an infestation of young pods by the fungus Botrytis in the second year. We quantified the number of pods, seeds, and seed weight produced in these experiments. Pods were collected and kept in a refrigerator for five days and weighed on an analytical balance KERN EMB 500-2S (precision $0.01 \mathrm{~g}$ ).

\section{STATISTICAL ANALYSIS}

For each species, we calculated the rates of legitimate visits and robbery, but only for the period where the flowers were open. Nevertheless, we also analysed total robbery during the flower's 
lifespan by including the occurrence of nectar robbery events when the flowers were closed. We used the Pearson correlation test to estimate the relationship between the flowers lifespan (hours) and the number of nectar robberies, as well as between the number of legitimate visits and the number of robbery events. Since the data were normally distributed, we used an ANOVA to compare the duration of legitimate visits recorded for A. mellifera across both days and years, comparing these effects a posteriori using a TukeyHSD test. We used a non-parametric pairwise Wilcoxon Rank Sum test to compare robbery time (seconds) among days and years as these data were not normally distributed. For nectar robbery, we merged the information for $A$. mellifera and $B$. terrestris, as the average time dedicated to robbery was comparable at $3.12 \pm \mathrm{SE}$ 0.12 seconds for $A$. mellifera, and $3.35 \pm$ SE 0.16 seconds for $B$. terrestris. Because the lifespan of $V$. faba flowers varies between 2 and 4 days, we compared the number of legitimate visits and robbery events for each hour of life. We compared the number of $\mathrm{DK}=1$ and $\mathrm{NDK}=0$ behaviour per species and day of flower lifespan, using contingency tables and chi-square tests.

To test for variation in bee behaviour (i.e. legitimate visits or robbery as response variable) between years (numerical predictor) and bee species (B. terrestris and A mellifera used as fixed categorical predictor), we performed a General Linear Model (GLM). First, we used the entire dataset of all observed flowers $(N=64)$. In the second analysis, we focused on a subset of flowers $(N=23)$, selecting those with visitation information available for their entire flowering period. For each model, we selected the most appropriate distributions (Gaussian, Poisson and negative binomial distribution) by contrasting the Akaike Information Criterion (AIC) of alternative models. Tukey test was subsequently applied for multiple comparisons of the variables over both years. We applied one model for both $B$. terrestris and $A$. mellifera, because they were the two main visitors, and one model (total) for all the bee species. In these models, we included "year" as a fixed effect to account for interannual population variation of A. mellifera and Bombus spp., possibly due to them sharing common pathogens (see Smith-Ramírez et al. 2014 and Smith-Ramírez et al. in preparation). We assessed goodness-of-fit of the selected model by running a likelihood ratio test comparing it to the null model, similar to Burnham \& Anderson (2002) and Wagenmakers \& Farrell (2004). GLMs were fitted using the $\mathrm{R}$ packages: MASS (4.0, Venables \& Ripley 2002), Matrix (1.3-4, Bates et al. 2021), nlme (3.1-152, Pinheiro et al. 2021), Hmisc (4.5-0, Harrell 2021) and the MuMIn (1.43.17, Barton 2021) package for model averaging.

The numbers of pods per flower observed under open, self and cross-pollination were compared with a simple logistic regression, as the data were binomial. The number of seeds per pod and seed weight between open and artificial crossed visits was compared by Wilcoxon tests following a logistic distribution (no data were normal or able to be normalized). We analysed all data using $\mathrm{R}$ Studio, Inc. (Version 1.2.5033; R version 3.6.1 ( $R$ Core Team 2019)). The significance used by all the test was $P$-value $<0.05$, we considered marginally significant $\mathrm{p}$-value between 0.05 to 0.1 .

\section{RESULTS}

\section{DIVERSITY, ABUNDANCE AND GENERAL BEHAVIOUR}

A total of seven species were recorded by camera and on-site observer methods visiting $V$. faba flowers in the two years (Table 1). We found four Apidae species: three introduced species $A$. mellifera, $B$. terrestris and $B$. ruderatus, and one native bumblebee $B$. dahlbomii; two native Colletidae: Cadeguala occidentalis and Cadeguala albopilosa, and one Halictidae Corynura spp. (the latter was recorded by human rather than camera observations (Table 1)). The main visitor of $V$. faba was $B$. terrestris, but the main pollinators in both years were $A$. mellifera, followed by $B$. terrestris (Table 1$)$. B. terrestris was generally a primary nectar robber, and A. mellifera was a secondary robber. We observed neither native pollinators nor B. ruderatus robbing nectar (Table 1). The relative frequency of legitimate visits by B. ruderatus was low, $3.39 \%$ and $2.38 \%$ in years one and two, respectively, visiting $37.04 \%$ in 2018 and $45.95 \%$ in 2019 of the flowers observed by cameras. The frequency of legitimate visits recorded for $C$. occidentalis was also low, accounting for $0.56 \%$ of the visits and $16.22 \%$ of the flowers observed by cameras (Table 1). Legitimate visits and robbery from exotic Apidae occurred mainly from 16:00 to 20:00, slightly out of phase 
Table 1. Legitimate visits and robbery activity (when flowers are open) in a Vicia faba field. The total number of flowers in anthesis and buds recorded with cameras was 27 in 2018 and 37 in 2019. The total time recorded was 155.93 hours of anthesis in year one and $334.70 \mathrm{~h}$ in year two. A. = Apis, B. = Bombus, C. = Cadeguala. Lv = Legitimately visited, rob = robbed. In the observations made by on-site observer method, to standardize the visit rate, the average number of flowers per plant was 14.08 \pm 0.68 .

\begin{tabular}{|c|c|c|c|c|c|c|c|c|c|c|}
\hline & Species & $\begin{array}{c}\text { Only } \\
\text { rob } \\
\text { flowers }\end{array}$ & $\begin{array}{c}\text { Onl Lv } \\
\text { flowers }\end{array}$ & $\begin{array}{l}\text { Lv + rob } \\
\text { flowers }\end{array}$ & $\begin{array}{c}\text { Total } \\
\text { fv } \\
\text { flowers }\end{array}$ & $\begin{array}{l}\text { Lv } \\
\text { flowers } \\
\text { (hour-1) }\end{array}$ & $\begin{array}{l}\text { Total } n^{\circ} \text { of } \\
\text { legitimate } \\
\text { visits }\end{array}$ & $\begin{array}{l}\text { Total } n^{\circ} \\
\text { of } \\
\text { robberies }\end{array}$ & $\begin{array}{l}\text { Legitimate } \\
\text { visit rate } \\
\text { (flower-1 } \\
\text { hour-1) }\end{array}$ & $\begin{array}{c}\text { Robbery } \\
\text { rate } \\
\text { (flower-1 } \\
\text { hour-1) }\end{array}$ \\
\hline \multicolumn{11}{|c|}{ Observations made by cameras } \\
\hline \multirow[t]{4}{*}{ Year 1} & A. mellifera & 5 & 0 & 21 & 21 & 0.13 & 100 & 142 & 0.02 & 0.03 \\
\hline & B. terrestris & 4 & 0 & 9 & 9 & 0.06 & 23 & 47 & 0.006 & 0.01 \\
\hline & B. ruderatus & 0 & 10 & 0 & 10 & 0.06 & 15 & 0 & 0.004 & \\
\hline & B. dahlbomii & 0 & 1 & 0 & 1 & 0.006 & 1 & 0 & 0.0002 & \\
\hline \multirow[t]{4}{*}{ Year 2} & A. mellifera & 0 & 15 & 22 & 37 & 0.11 & 222 & 9 & 0.02 & 0.0007 \\
\hline & B. terrestris & 5 & 0 & 25 & 25 & 0.08 & 163 & 723 & 0.01 & 0.06 \\
\hline & B. ruderatus & 0 & 17 & 0 & 17 & 0.05 & 30 & 0 & 0.002 & \\
\hline & C. occidentalis & 0 & 6 & 0 & 6 & 0.03 & 7 & 0 & 0.0006 & \\
\hline \multicolumn{11}{|c|}{ Observations made by people } \\
\hline \multirow[t]{3}{*}{ Year 1} & A. mellifera & - & - & - & - & - & 4 & 38 & 0.0006 & 0.006 \\
\hline & B. terrestris & - & - & - & - & - & 1 & 70 & 0.0002 & 0.01 \\
\hline & C. albopilosa & & & & & & 1 & 0 & 0.0002 & \\
\hline \multirow[t]{3}{*}{ Year 2} & A. mellifera & - & - & - & - & - & 9 & 0 & 0.001 & \\
\hline & B. terrestris & - & - & - & - & - & 0 & 91 & & 0.01 \\
\hline & C. chilensis & - & - & - & - & - & 4 & 0 & 0.0005 & \\
\hline
\end{tabular}

with the period of maximum flower opening (Fig. 1A and $\mathrm{B}$ ). The visits of the native bees recorded by cameras occurred between 18:00 to 19:00. However, on-site observers have noticed midday activity for native bee species. The percentage of flowers pollinated within ten plant plots, during the morning to midday, was $17.49 \%$ $(N=14$ flowers in all the observation time over both years; Table 1). However, using camera methods, we found that $78.28 \%$ of the flowers were visited (52 from 64 flowers, Appendix IA), and $100 \%$ of them received at least one legitimate visit during their lifespan.

Adding both years and methods, we found 1,615 visits (legitimate visits plus robbery; Table 1 ). Approximately $1 / 3(N=580)$ were legitimate, and from this nearly $1 / 3(N=187)$ from $B$. terrestris. Of the total visits of $B$. terrestris (legitimate visits plus robbery, $N=1118), 83.27 \%$ were robbery when flowers were open $(N=937$; Table 1 , Appendix I
A). Bombus terrestris also robbed nectar 373 times while flowers were in bud (closed) and 24 times (robbed or tested there is nectar) in recently senescent flowers (Appendix I B). Overall, the percentage of visits by $B$. terrestris robbing nectar (open and close flowers) was $87.66 \%$. In contrast, A. mellifera robbed open flowers $33.2 \%(N=164)$, and robbed closed or recently senescent flowers principally in the first year ( $N=112$ times).

LEGITIMATE VISITS AND ROBBERY PER YEAR, AND DURING THE LIFETIME OF THE FLOWERS

In year one, $33.33 \%$ of studied flowers received at least one legitimate visit by B. terrestris. In year two, this number doubled to $67.57 \%$ (Table 1). Year one had notably less activity than year two, in both legitimate visits and nectar robbery. This difference was mainly due to $B$. terrestris which had almost twice the number of legitimate visits and six times more robbery in the second year (year one: $0.005 \mathrm{fv} / \mathrm{h} /$ flower (legitimate visits per 

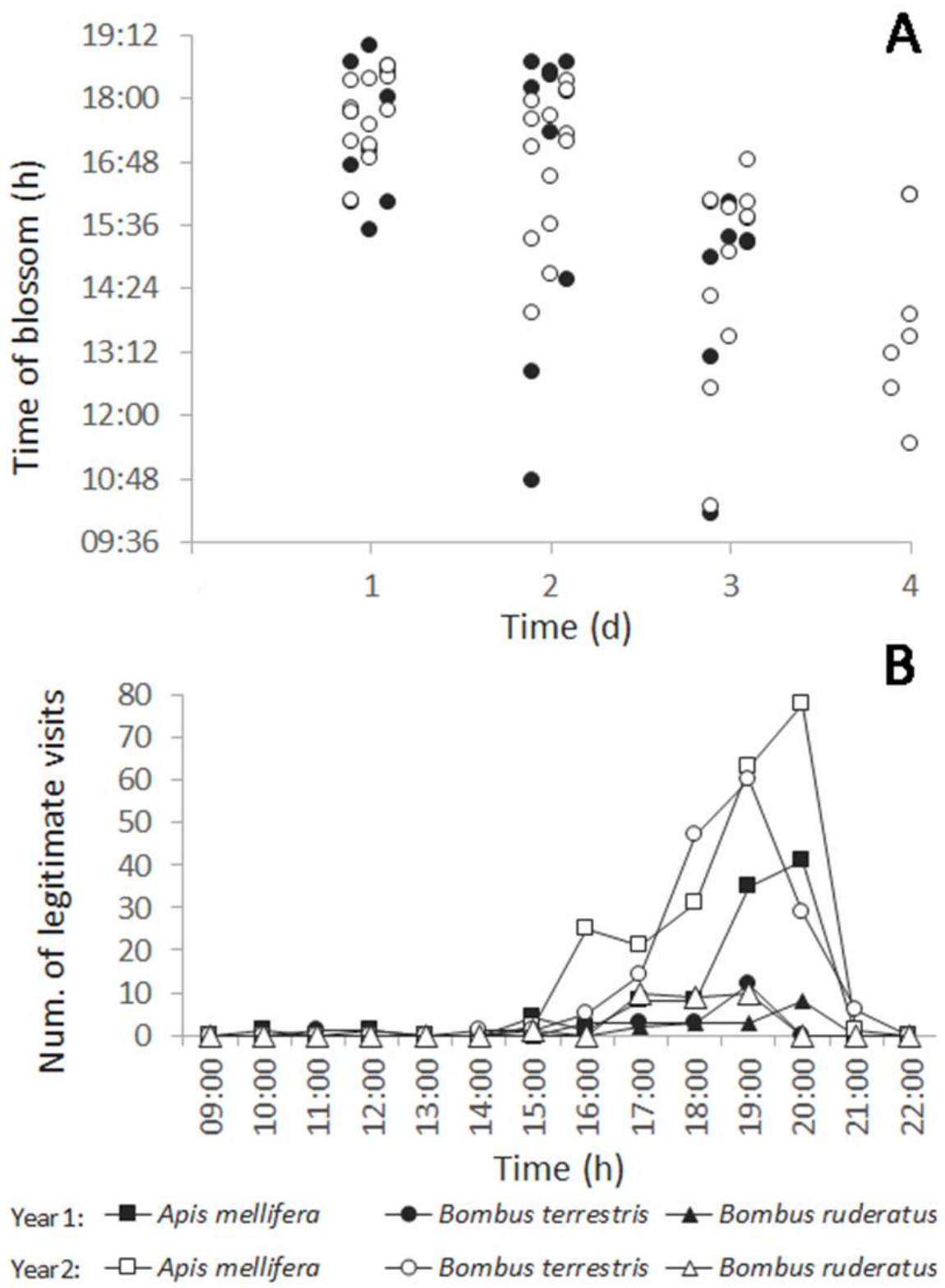

Figure 1. (A) Time of the day when flowers opened during the flower life for each study year. Black circles for year one; white for year two. (B) The number of legitimate visits for the main pollinator species of Vicia faba, for each hour and all flowers studied in both years. hour per flower); $0.01 \mathrm{rob} / \mathrm{h} /$ flower; year two (robbery events per hour per flower): 0.01 $\mathrm{fv} / \mathrm{h} /$ flower; $0.06 \mathrm{rob} / \mathrm{h} /$ flower) with many visits concentrated over a few flowers (Appendix I A; Table 1).

GLM analysis, using a negative binomial distribution, showed that the main legitimate visits were made by $A$. mellifera, especially in year one (Appendix II). Legitimate visiting behaviour was affected by the interaction between pollinator species and year, accounting for $77 \%$ of the observed variance by Akaike weight (Appendix II). Robbery behaviour was affected by pollinator species, year and their interaction. For robbery, the interaction accounted for $100 \%$ of the observed variance (Appendix II). Apis mellifera was the main bee in terms of robbing behaviour in the first year (2018) (Table 1, Fig. 2B), while in year two, B. terrestris was the main bee robbing flowers.

The flowers were alive for a maximum of four days; on average, they were open at $11.97 \pm 0.15$ hrs, for a minimum of two and a maximum of eight hours per day. Apis mellifera typically made legitimate visits during the lifetime of the flowers. However, B. terrestris tended to show a reduction in the number of legitimate visits with the age of the flower in year two, which contrast with the pattern observed for nectar robbery (Figs. 2A and 3A; Kruskal-Wallis, df =2, $P=0.06$ ). 


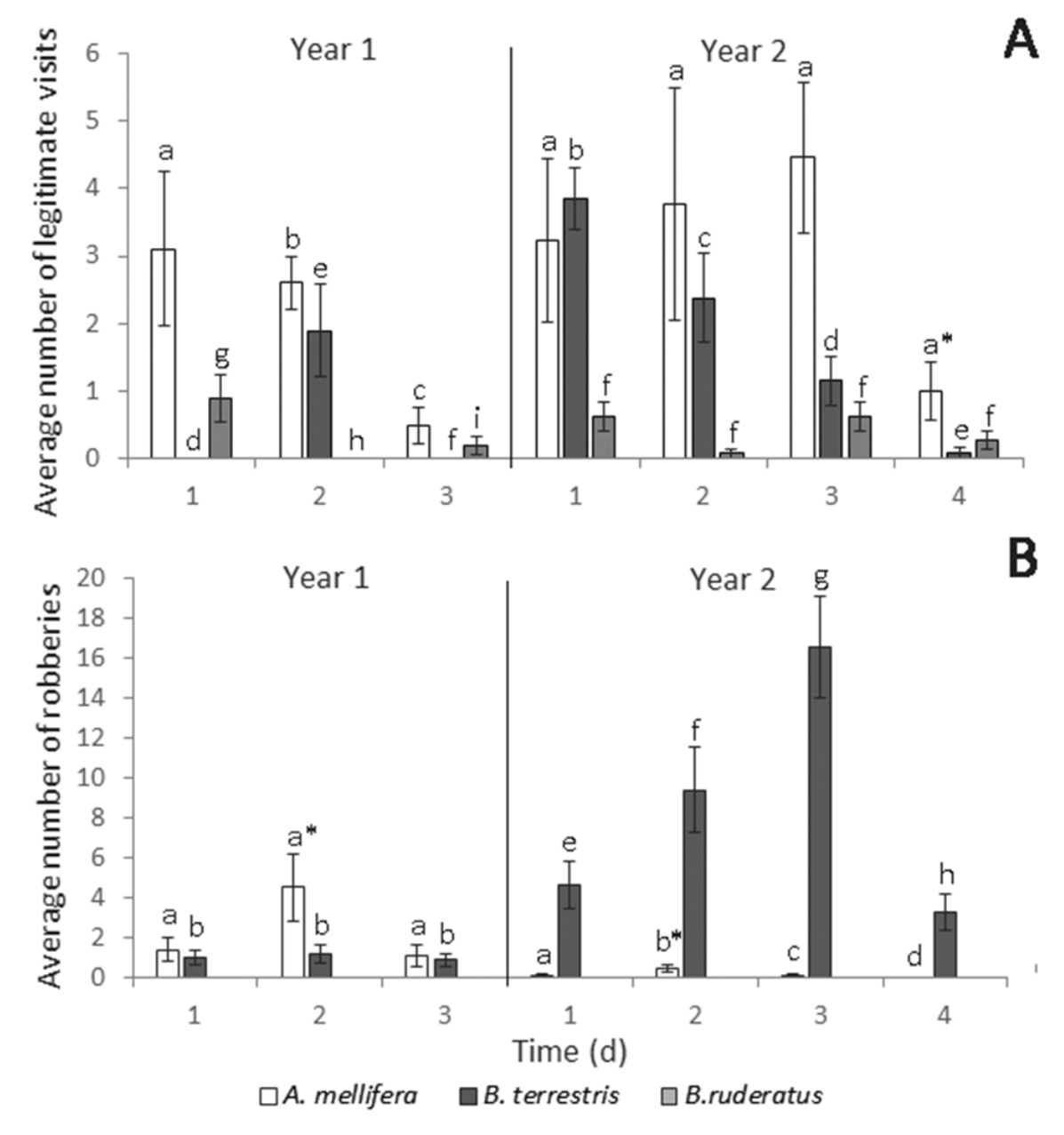

Figure 2. Average absolute number ( \pm standard error) of (A) legitimate visits and (B) nectar robbery events by Apis mellifera, Bombus terrestris and $B$. ruderatus on open flowers of Vicia faba during each day of flower life in both study years (recorded by cameras). The same letters above bars mean there is no statistical differences, $P<$ 0.05. Marginal p-values (between 0.05 to 0.1 ) are showed with an asterisk (*). Different letters mean significant differences.

Considering that legitimate visits produce fertilized ovules only from the second until last day of a $V$. faba flowers' lifespan, A. mellifera made on average $1.55 \pm 0.8$ legitimate visits per flower for these days in year one (ranging from 0 to 4 visits), and on average $3.19 \pm 0.7$ legitimate visits in year two (ranging from 0 to 20 visits). Bombus terrestris showed an average of $0.95 \pm 0.4$ legitimate visits per day in year one. However, counting only days two and three (there were no legitimate visits on day four), this was $0.86 \pm 0.61$ ( 0 to 6 visits), and in year two, the average was $1.27 \pm 0.78$ for days 2,3 and $4,(0$ to 7 visits). For B. ruderatus, we found that most of the pollination events were performed on the first day of flower opening (Fig. 2A). Considering all active pollinators between days two and four, the flowers received on average 2.60 \pm 0.67 legitimate visits during year one and $4.46 \pm$ 0.93 in year two. The number of robberies that each flower received during its life was 4 to 96 , in average $23.70 \pm 3.99$, with more robbery events in year two (Table 1).
GLM analysis of the subset of flowers showed that legitimate visits were affected by the interaction between pollinator species and year (Appendix III). For days one, three and the total lifespan, Akaike weight accounted for 99\%, 56\% and $68 \%$ of the variability, respectively (Appendix III). Day two was influenced only by pollinator species, accounting for $43 \%$ of the observed data (Appendix III). The best-fit models for nectar robbery during the life of flowers always included the interaction term between pollinator species and year. For both day and total days, the interactions explained $100 \%$ of observed data by Akaike weight (Appendix III). Depending on the species there was a significant decrease in the legitimate visits on days three (Appendix III, Fig. 3B) or four.

There was a positive Pearson correlation between the number of legitimate visits and number of robbery visits during the flower lifespan $(t=2.56, P=0.018)$. This significant correlation occurred over the first 14 hours of 

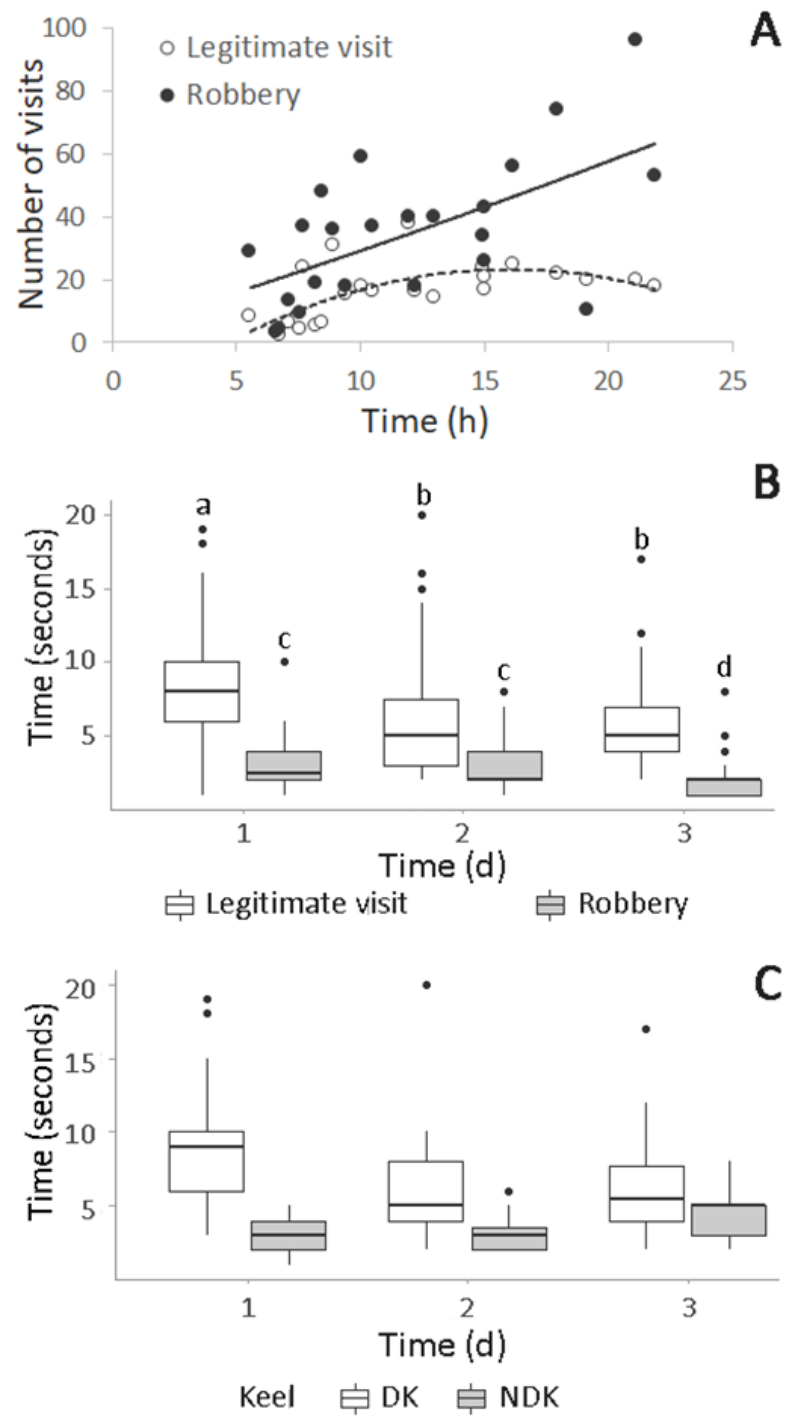

Figure 3. (A) Correlation between the time of a flower's life (hours) and the number of legitimate visits to the flower (white circles, tendency in dotted line) and nectar robbery per flower including robbery to buds, open, closed and dead flowers (black circles, tendency in continuous line). (B) Box plots of total time spent by pollinators on legitimate visits (Apis mellifera) and robbery (A. mellifera and Bombus terrestris) in a flower's life. Circles represent outliers. (C) Box plots of total time spent by $A$. mellifera down and non-down the keel (DK and NDK respectively) in a flower's life. Error standard is showed, and circles represent outliers.

flower life (Pearson correlation between the flower lifespan (hours) and robbery numbers: $\mathrm{t}=3.39, P=$ 0.002). However, after 14 hours, we notice the opposite trend with robbery increasing while legitimate visits decrease (Fig. 3A).

The behaviour of both A. mellifera and $B$. terrestris was almost exclusively either foraging or collecting nectar by robbery, or for pollen by legitimate flower visits. Individuals rarely went for both resources in the same visit to a flower or any other flower in close proximity. When following individual insects, we recorded up to 22 nectar robbery events without any pollination, and up to 12 legitimate visits without any robbery (after that, we lost the individuals of our view). On cameras, we recorded that from a sample of 102 visits; only in four cases $(3.92 \%)$ did the visitors pollinate the same flower that they robbed nectar from.

TIME SPENT IN LEGITIMATE VISITS, POLLINATION VISITS AND IN NECTAR ROBBERY DURING THE LIFE OF THE FLOWER

The time spent by the main pollinator $(A$. mellifera) in legitimate visits during year one showed no significant difference between the days over which the flower was open, but there was some suggestion of a trend of decreasing visitation over time (Day 1: $10.60 \pm 1.65$, from $5 \mathrm{sec}$. to $19 \mathrm{sec}$; Day 2: $7.26 \pm 1.28$, from 2 sec. to $20 \mathrm{sec}$; Day 3: 5.50 \pm 1.32 , from $3 \mathrm{sec}$. to 9 sec; p-value Pairwise Wilcoxon Rank Sum test ranked from 0.13 to 0.97). In year two, however, the time spent was significantly higher on day one than the other days (Day 1: $8.31 \pm 0.66$, from $1 \mathrm{sec}$. to $18 \mathrm{sec}$; Day 2: 6.19 \pm 0.71 , from 2 sec. to $20 \mathrm{sec}$; Day 3: $5.60 \pm 0.43$, from $2 \mathrm{sec}$. to $17 \mathrm{sec}$; p-value for day one compared to day two was $0.007,0.001$ compared day 1 to day 3; but day 2 and 3 were similar $P=0.7$ ). Adding data for both years together (Fig. 2A) showed on average that the trend was dominated by a year effect, with significant differences in visitation between days (ANOVA, $\mathrm{F}=11.67, \mathrm{df}=2, P<$ $0.0001)$. TukeyHSD showed that day 1 was different from days 2 and $3(P=0.03$, diff $=-0.33$, lower $=-0.63$, upper $=-0.02$ and $P<0.0001$, diff $=-$ 0.62 , lower $=-0.91$, upper $=-0.33$, respectively) .

We observed that for A. mellifera $29.87 \%$ of legitimate visits (average of the three days of flower life) did not lower the keel (NDK; Fig. 4A). These percentages were significantly different across days (chi-square test $=13.76, \mathrm{df}=3, P=0.03$ ). For NDK behaviour, the honeybee was in the wind pushing the banner gently, spending half the time (in average 3.87 seconds \pm 0.38 ) than when the bee lowered the keel completely (in average 7.82 seconds \pm 0.61 ). The average time where DK behaviour was performed was different from NDK $(\mathrm{W}=59.5, P=0.002$; Fig. 3C). We also observed that, especially for days two and three, $25.96 \%$ of the visits of the honeybees were of only two to three seconds duration. NDK behaviour was observed 


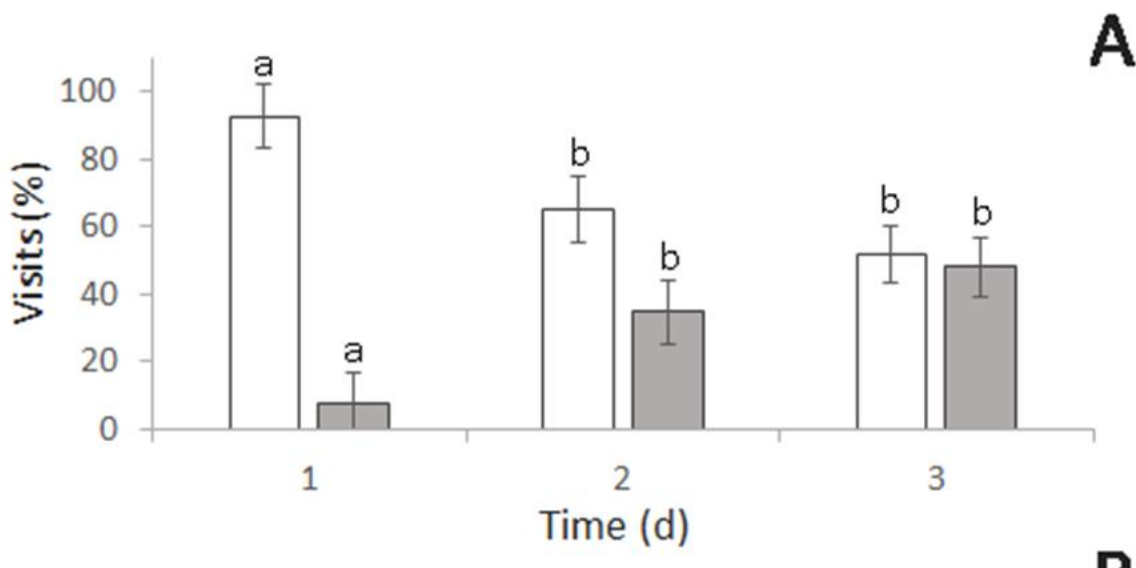

A

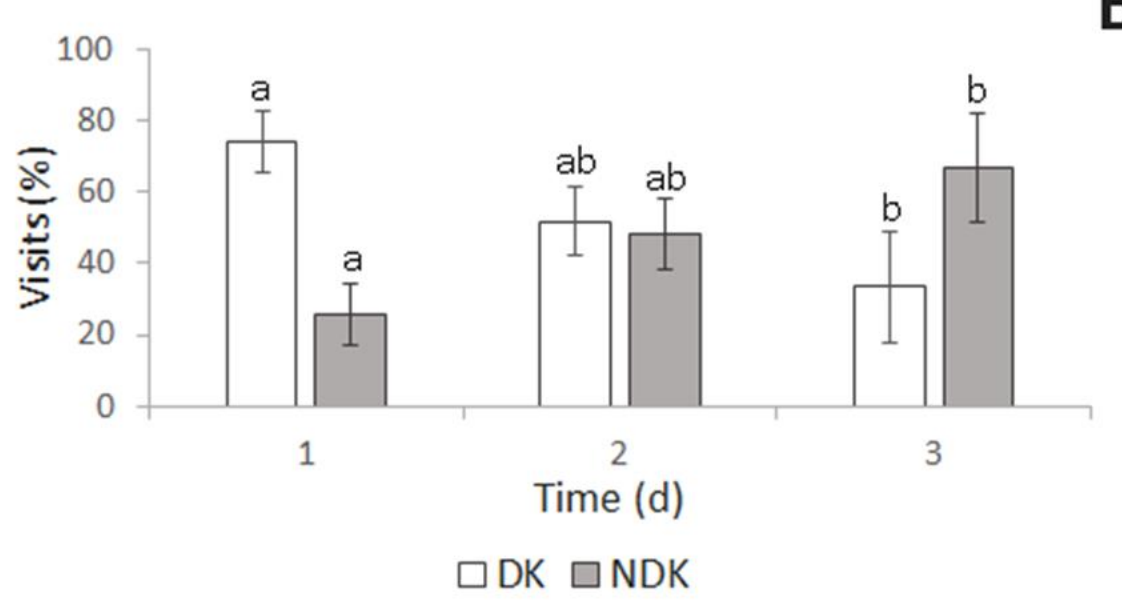

Figure 4. Percentage of the behaviour by Apis mellifera (A) and Bombus terrestris (B) to down completely (DK) and not to down completely the keel (NDK) of V. faba flowers along three days of its life. When the insect lowers the keel, he collects pollen. For A. mellifera and $B$. terrestris day was a significant factor using logistic regression $(P=0.0008$ and $P=0.02$, respectively). The first day was different for A. mellifera (Wilcoxon, $P=0.03$ compared to day 2 and $P=$ 0.003 compared to day 3 ), day 2 and 3 were similar $(P=0.3)$ and for $B$. terrestris, only day 3 is marginally different from day $1(P=0.09)$. The standard error is shown.

in $B$. terrestris $39.71 \%$ of the time (average of the three days; Fig. 4B), for a duration of one to five seconds.

The time spent by $B$. terrestris and A. mellifera in nectar robbery during year one were similar across the three days of the flower lifespan (Day 1: $2.78 \pm$ 0.22 , from 1 sec. to $6 \mathrm{sec}$; Day 2: $2.90 \pm 0.21$, from 1 sec. to $7 \mathrm{sec}$; Day 3: $2.62 \pm 0.35$, from 1 sec. to $8 \mathrm{sec}$; $P$-values using Pairwise Wilcoxon Rank Sum ranked from 0.45 to 0.95$)$. However, the time spent each day undertaking nectar robbery in the second year was different. On day three, both bumblebee species spent significantly less time undertaking nectar robbery than days two and one (Day 1: 3.07 \pm 0.47 , from $1 \mathrm{sec}$. to $10 \mathrm{sec}$; Day 2: $2.82 \pm 0.36$, from $1 \mathrm{sec}$. to $8 \mathrm{sec}$; Day 3: $1.50 \pm 0.15$, from $1 \mathrm{sec}$. to $3 \mathrm{sec}$; $P$-value of day three was 0.01 for both comparisons, day one and two had a $P=0.94)$. We combined data across both years to produce Fig. 3B. In this case, the trend was significantly higher during the first and second day than the third (Kruskal-Wallis, df $=2, P=0.0005$, Wilcoxon pairwise day three compared with days one and two was similar, $P=0.001$ ).

\section{POLLINATION ASSAYS}

We counted more pods, more seeds per pod and heavier seeds for those flowers that received open pollination compared to those with the selfpollination treatment. Overall, 33.33\% (30 flowers) of marked flowers in open-pollinated assays and $5.08 \%$ of self-pollinated flowers (six flowers) produced pods. These differences were significant (W $=174, P<0.001)$. On average, more seeds per pod $(N=0.53)$ were counted in open pollination compared to self-pollination assays, but the differences were marginally significant, mainly due to the low number of seeds observed in the self-pollination assay $(\mathrm{W}=242.5, P=0.074)$. Seeds in open pollination were heavier than selfpollination, although these differences were marginally significant ( $W=1019, P=0.059$; Fig. 5).

\section{Discussion}

In this study, we found that the main interaction behaviour of $B$. terrestris when foraging on $V$. faba flowers was nectar robbery, a result that was far higher in this system when compared to 


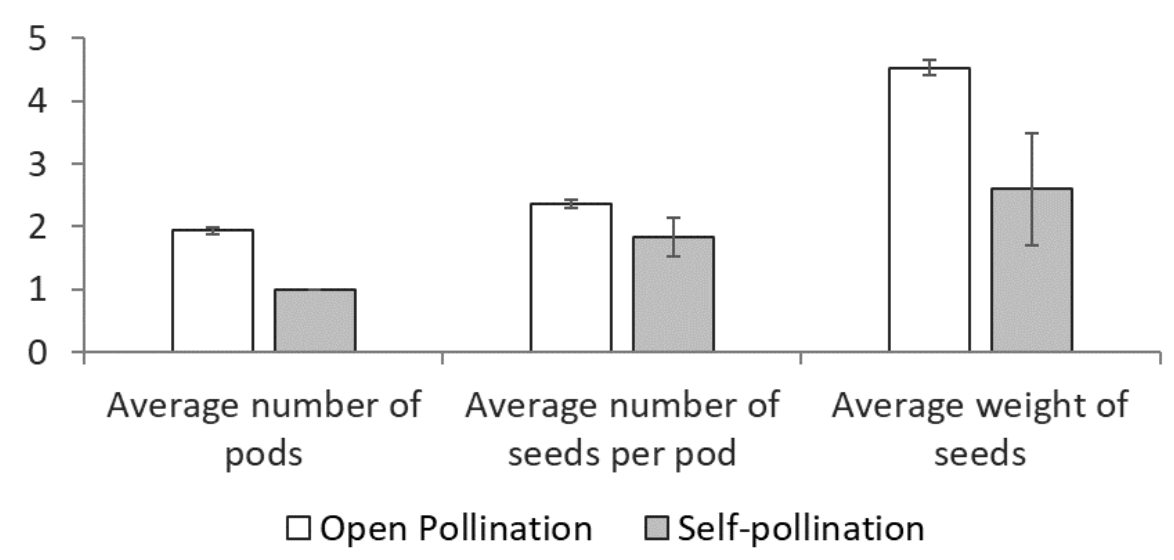

Fig. 5. The average number ( \pm standard error; right), seed numbers ( \pm standard error; middle), and weight (gr; \pm standard error; left) of pods produced per inflorescence of $V$. faba in open pollination and self-pollination assays.

other studies. The visitation rate of $B$. terrestris varied significantly between years. We found evidence that suggested that competition for pollen and nectar is happening after the first and second day of the flower lifespan, respectively, especially in the year when $B$. terrestris is found in high abundance. Bombus terrestris was mainly a floral parasite of $V$. faba. In most cases, even when legitimate visits occur, the pollinator fails to move the flower keel (a necessary pre-requisite for successful pollination). In addition, the high demand of resources that this species needs is likely to prevent other pollinators from visiting and pollinating the flower.

Overall, there was a low diversity and abundance of native pollinators. It is likely that before the arrival of $B$. terrestris, the main pollinator of $V$. faba was the long-tongued bumblebee, $B$. dahlbomii. Interviews with Mapuche gardeners suggest that $B$. dahlbomii is or was the main pollinator of $V$. faba in rural areas $170 \mathrm{~km}$ north of the garden studied here (B. Chicori pers. Comm., indigenous leader). In 2019, we observed abundant B. dahlbomii on $V$. faba flowers in northern Chiloé Island (around $108 \mathrm{~km}$ south of the field studied). It is highly likely that $B$. dahlbomii pollination in $V$. faba has been replaced by both the long-tongued bumblebee $B$. ruderatus and the short-tongued B. terrestris.

In a garden experiment conducted in Germany, the frequency of nectar robbery by $B$. terrestris compared to legitimate visits was high at $67.4 \%$ (Marzinzig et al. 2018). In Finland, the frequency was nearly $60 \%$ (without considering extra-floral visits, Lönnqvist 2019). These percentages are lower than what we found in our study $(87.19 \%)$, and this is probably related to the high abundance of this invasive insect in south-central Chile and Argentina. We have no explication about why $A$. mellifera was identified as undertaking nectar robbing behaviour in the first but not in the second year. However, one possibility is that the higher abundance of $B$. terrestris during the second year could have altered the behaviour of A. mellifera, although it could be related with changes in resources. The high abundance of $B$. terrestris observed in 2019 was also found in eight other $V$. faba fields located in Osorno province (RendónFunes et al. manuscript in preparation), in Valdivia gardens $(100 \mathrm{~km}$ north our study site (Ramires unpublish data)) and in Chiloé Island (200 km south our study site; Smith-Ramírez et al. manuscript in preparation).

High inter-annual changes in the relative abundance of B. dahlbomii, Apis and B. terrestris has been described in a long-term study by SmithRamírez et al. (2014). In the case of B. terrestris, while we see an overall increase in abundance (Montalva et al. 2017), there is an up and down (primary order) inter-annual dynamics (Ramires 2019). In 2018, the abundance of B. terrestris was lower than in 2019. Because our study sites and the surrounding landscape had only wild colonies of $B$. terrestris and A. mellifera, our observations are likely to be representative of natural population changes rather than the effect of importation of commercial colonies of either species.

Our results suggest that intra- and inter-specific competition for resources, both for pollen and nectar, occurs in years when $B$. terrestris is found in high abundance and pollen limitation precedes nectar limitation. Pollen is a more limited resource 
than nectar because the former is not replenished over the lifetime of the flower. However, it is the occurrence of pollen that makes tubular flowers, including those of $V$. faba, attractive to shorttongued bees as Apis and Cadeguala. We also found that after the first day of the flower becoming a viable resource for bees, the time spent in legitimate visits by A. mellifera decreased, but only in year two. Evidence for some level of increase in the number of robbery visits during the lifespan of the flower probably may indicate that nectar production in $V$. faba has been stimulated by the ongoing extraction (as shown in Pierre et al. 1996). We found that pollinators spend less time in nectar robbery on the third day after flower onset, but only for the year with the highest abundance of $B$. terrestris. It is likely that there is a limit in the standing crop of nectar that a flower can produce, and after an average of 23 nectar robbery visits per flower (but up to 96 visits), continued nectar production is beyond the flower's capacity. Our results suggest that by the third day, visiting pollinators may still be searching for nectar, but after this, a reduction in nectar resources results in a decline in subsequent robbery events. Even during the first day, some pollinators spend as little as one second robbing some flowers. This may also be indicative that nectar has become a limited resource, and competition for nectar can occur at this stage in some years. Given the high rate of robbery observed in B. terrestris, it is unlikely that the number of legitimate visits can be sufficient to increase yields in this system.

It has been reported in Europe that $V$. faba flowers live six to seven days, being open 31.5 to 35.5 hours (Stoddard \& Bond 1987; Pierryman \& Marcellos 1988). In comparison, we found that the flowers of the cultivar studied lived three, and exceptionally four days, and that flowers were open for about 12 hours over this period in total. If we consider that the main activity of pollinators occurred in the portion of the day when $V$. faba flowers are open, then for the cultivar studied (one the most common in the Chilean family-gardens), this represents only a limited amount of time during which cross-pollination could occur (Stoddard 1986).

A low frequency of legitimate visits to $V$. faba has been reported by several authors as one of the reasons for the small and unstable yields of this legume (Scriven et al. 1961; Poulsen 1975; Mesquida et al. 1990; Suso et al. 2001 and many others). Suso et al (2001) studied six $V$. faba fields in Spain and six more in France, observing the flowers in periods of five minutes intervals over the entire flowering period. They found that on average, 1.9 to $8.5 \%$ of flowers in Spain, and 11.1 to $27.5 \%$ in France, received pollinator visits. We estimate that in our studied field, 70 to $100 \%$ of flowers received legitimate visits during the total observation period. This on-site result coincides with what we observed by cameras, with $100 \%$ of the flowers receiving legitimate visits during their lifespan. The average duration of a legitimate visit (excluding the first day) was 2.63 and 4.98 seconds in 2018 and 2019, respectively. However, one-third of them would have been unlikely to result in pollination. We do not know how many pollination visits are required for $V$. faba to be fertilized; however, our data suggest no over pollination of $V$. faba by B. terrestris, despite their high abundance. Vicia faba might even be pollinator-limited as the high abundance of $B$. terrestris may be displacing honeybees and native pollinators. We do not know why there is no increase in nectar foraging in the morning as $V$. faba flowers replenish the nectary early in the morning and afternoon (Stoddard \& Bond 1986). It might be that the high foraging rate at sunset limits the capacity of the flower to refill the nectary by the next morning.

Although we did not obtain conclusive results from the cross-pollination experiment, we found that self-pollination decreases the production of pods, seed number and seed weight compared to open pollination. We propose that crosspollination would probably be greater at lower abundance of $B$. terrestris, as this would allow greater abundances of $A$. mellifera and other pollinators to occur. Our results suggest that where high abundance of $B$. terrestris occurs, the resulting reduction in flower resources available for other pollinators could promote competitive displacement.

It has been proposed that $B$. terrestris contributes positively to the pollination of $V$. faba crops in Finland because the perforation in the base of nectary is necessary to induce legitimate visits (Kyllönen 2018). We think that in Chile this is not true, since B. terrestris is highly abundant, 
which leaves little nectar available for the use of other pollinators, a result also found by Sáez et al (2017) in a South Argentina raspberries field. In our study, we also recorded some expulsions of $A$. mellifera from $V$. faba flowers by $B$. terrestris in the second year when $B$. terrestris was most abundant, but this was not frequent. Displacement of native pollinators (interference competition) by $B$. terrestris has also been mentioned by Dafni \& Schmida (1996), but not found by Hingston \& McQuillan (1999). Also, B. terrestris is not likely to be a good pollinator in this system despite its high abundances, reflecting the fact that approximately $50 \%$ of flowers did not receive any legitimate visits during their entire lifespan, with a further third of these legitimate visits being of a quality unlikely to lead to seed set (bees did not displace the flower keel).

In conclusion, this study suggests that in the case of $V$. faba in South-central Chile, the decrease in the time foraging for nectar or collecting pollen over the lifespan of the flower is evidence for some level of resource limitation. To our knowledge, only one other study has identified competitive displacement of other pollinators by $B$. terrestris, looking at the impact on two native Megachilidae in Tasmania and concluding that displacement happened because of competition for a limited resource (Hingston \& McQuillan 1999). If such competitive exclusion continues to be an issue, it is likely that the continued increase of $B$. terrestris populations in Latin America (Montalva et al. 2017) will exacerbate resource competition with native pollinators. As much of the $V$. faba crops are grown for local consumption, this may negatively impact food resources, an unexpected result given the ever-increasing populations of this invasive pollinator species.

\section{ACKNOWLEDGEMENTS}

We thank Claudio Espinoza, who gave us the opportunity to work in his family garden. Also, we thank José Montalva, who inspired this study, Carlos Valdivia for his worthy talk about pollination, Lorena Vieli for lending us her cameras, field and lab assistants, Rafael Cárdenas for his help with the statistics, as well as Reto Schmucki and Ben Woodcock for improving the English. We also thank the two anonymous reviewers and the journal editors. This study was supported by Universidad de Los Lagos, project R25/18, and by the Instituto de Ecología y Biodiversidad (IEB), AFB170008, AFB170008 and FB210006. CSR also received support from SURPASS2, a project funded under the Newton Fund Latin America Biodiversity Programme: Biodiversity - Ecosystem services for sustainable development, awarded by the UKRI Natural Environment Research Council (NERC grant: NE/S011870/2), in partnership with the Argentina National Scientific and Technical Research Council (CONICET), Brazil/São Paulo Research Foundation (FAPESP), and Chile National Agency for Research and Development (ANID).

\section{AUTHOR CONTRIBUTION}

C.S.R., A.R. and R.B. wrote the manuscript; A.R. compiled the data. A.R., R.B. and W.M. led the statistical analysis; C.S.R., A.R., R.B. and W.M. did field samples; All the authors contributed critically to the draft and gave final approval to the publication.

\section{APPENDICES}

Additional supporting information may be found in the online version of this article:

Appendix I. Number of legitimate visits and nectar robberies when the flowers were open and closed.

Appendix II. Generalized linear models (GLM) used to test the effect of year and pollinator species

Appendix III.The results of GLM analysis with factors

\section{REFERENCES}

Aizen MA, Smith-Ramírez C, Morales CL, Vieli L, Sáez A, Barahona-Segovia RM, Arbetman MP, Montalva J, Garibaldi LA, Inouye DW, Harder LD (2019) Coordinated species importation policies are needed to reduce serious invasions globally: The case of alien bumblebees in South America. Journal of Applied Ecology 56: 100-106.

Ansoleaga M, Salinas B (2010) Resultados y lecciones en producción de Habas tipo Baby. Proyecto de innovación en zona centro y centro-sur. Serie de experiencias de innovación para el emprendimiento agrario. Fundación para la innovación agria. Ministerio de Agricultura, Chile. 34 pp. Link: https://www.opia.cl/static/website/601/articles75604 archivo 01.pdf

Aouar-Sadli M, Louadi K, Doumandji SE (2008) Pollination of the broad bean (Vicia faba L. var. major) (Fabaceae) by wild bees and honey bees (Hymenoptera: Apoidea) and its impact on the seed production in the Tizi-Ouzou area (Algeria). African Journal of Agricultural Research 3: 266-272.

Arbetman MP, Meeus I, Morales CL, Aizen MA, Smagghe G (2013) Alien parasite hitchhikes to 
Patagonia on invasive bumblebee. Biological Invasions 15: 489-494.

Bartomeus I, Potts SG, Steffan-Dewenter I, Vaissiere BE, Woyciechowski M, Krewenka KM, ..., Bommarco R (2014) Contribution of insect pollinators to crop yield and quality varies with agricultural intensification. PeerJ, 2, e328.

Barton K (2020) Mu-MIn: Multi-model inference. R Package Version 1.43.17, $\underline{\text { https://CRAN.R- }}$ project.org/package=MuMIn

Bates D, Maechler M, Davis T, Oehlschlägel J, Riedy J, R Core Team (2021) Matrix: Sparse and Dense Matrix Classes and Methods. R Package Version 1.3-4, https://cran.r-project.org/web/packages/Matrix

Bishop J, Jones HE, Lukac M, Potts SG (2016) Insect pollination reduces yield loss following heat stress in faba bean (Vicia faba L.). Agriculture, Ecosystems \& Environment 220: 89-96.

Bommarco R, Marini L, Vaissière BE (2012) Insect pollination enhances seed yield, quality, and market value in oilseed rape. Oecologia 169: 1025-1032.

Bond DA, Poulsen MH (1983) Pollination. In: Hebblethwaite PD (ed) The Faba Bean (Vicia faba L.): A basis for improvement. Butterworth-Heinemann, London, pp 77-101.

Burnham KP, Anderson DR (2002). Modelselection and multimodel inference: A practical informationtheoreticapproach. New York: Springer-Verlag

Crépon $\mathrm{K}$, Marget $\mathrm{P}$, Peyronnet $\mathrm{C}$, Carrouée $\mathrm{B}$, Arese $\mathrm{P}$, Duc G (2010) Nutritional value of faba bean (Vicia faba L.) seeds for feed and food. Field Crops Research 115: 329-339.

Cunningham SA, Le Feuvre D (2013) Significant yield benefits from honeybee pollination of faba bean (Vicia faba) assessed at field scale. Field Crops Research 149: 269-275.

Dafni A, Shmida A (1996) The possible ecological implications of the invasion of.Bombus terrestris. In: Matheson A, Buchmann SL, O'Toole C, Westrich P, Williams IH (ed) The Conservation of Bees: 183-200. Academic Press.

FAO (2015) FAOstat: Crops. Vienna, Austria: Food and Agriculture Organization of the United Nations. Retrieved October 11, 2016, from http://www.fao.org/faostat/en/\#data/QC

Free JB (1966) The pollination requirements of broad beans and field beans (Vicia faba). The Journal of Agricultural Science, 66(3), 395-397.

Harrell F (2021) Hmisc: Harrell Miscellaneous. R Package Version 4.5-0, https://CRAN.Rproject.org/package $=$ Hmisc

Hingston A, McQuillan P (1999) Displacement of Tasmanian native megachilid bees by the recently introduced bumblebee Bombus terrestris (Linnaeus,
1758) (Hymenoptera: Apidae). Australian Journal of Zoology 47: 69-75.

Kendall DA, Smith BD (1975) The pollinating efficiency of honeybee and bumblebee visits to field bean flowers (Vicia faba L.). Journal of Applied Ecology 12: 709-717.

Kenis M, Auger-Rozenberg MA, Roques A, Timms L, Péré C, Cock MJW, Settele J, Augustin S, LopezVaamonde C (2009) Ecological effects of invasive alien insects. Biological Invasions 11:21-45.

Kyllönen $T$ (2018) Effects of pollination on pod distribution in faba bean (Vicia faba L.). Master's Thesis, Department of Agricultural Sciences, University of Helsinki. 63 p.

Lönnqvist A (2019) Pollinators Behaviour on Faba Beans. Thesis, HAMK Forssa, Sustainable Development, Finland.

Lunney D, Peegy E, Hutchingd P, Burgin S (2007) Pest or Guest: the cultural context of the zoology of overabundance. In: Dickman C, Lunney D, Burgin S (ed) Animals of the Arid Zone Out of their Own or Hungout? Royal Zoological Society of New South Wales, Australia, pp 258-269.

Manetas P (2000) Nectar Amount, Pollinator Visit Duration and Pollination Success in the Mediterranean Shrub Cistus creticus. Annals of Botany 86: 815-820.

Marzinzig B, Brünjes L, Biagioni S, Behling H, Link W, Westphal C (2018) Bee pollinators of faba bean (Vicia faba L.) differ in their foraging behaviour and pollination probability. Agriculture, Ecosystems and Environment 264: 24-33.

Mesquida J, Le Guen JN, Tasei S, Carre G, Morin Naeem M, Yuan X, Huang J, An J (2018) Modalités de la pollinisation chez deux lignées de féverole de printemps (Vicia faba L var equina Steudel). Effets sur les coulures, la productivité et les taux de croisements. Apidologie 21: 511-525.

Montalva J, Sepúlveda V, Vivallo F, Silva DP (2017) New records of an invasive bumble bee in northern Chile: expansion of its range or new introduction events? Journal of Insect Conservation 21:657-666.

Morales CL, Arbetman MP, Cameron SA, Aizen MA (2013) Rapid ecological replacement of a native bumble bee by invasive species. Frontiers in Ecology and the Environment 11: 529-534

Naeem M, Yuan X, Huang J, An J (2018) Habitat suitability for the invasion of Bombus terrestris in East Asian countries: A case study of spatial overlap with local Chinese bumblebees. Scientific Reports 8: 11035.

Nayak GK, Roberts SP, Garratt M, Breeze TD, Tscheulin T, Harrison-Cripps J, ..., Potts SG (2015) Interactive effect of floral abundance and semi-natural habitats on pollinators in field beans (Vicia faba). Agriculture, Ecosystems \& Environment, 199, 58-66. 
Newton SD, Hill GD (1983) Robbing of field bean flowers by the short-tongued bumblebee Bombus terrestris L. Journal of Apicultural Research 22: 124-129.

Perryman TC, Marcellos H (1988) The rhythm of flower opening in Vicia faba L. New South Wales Dept. of Agriculture, Tamworth (Australia), Agricultural Research Centre https://agris.fao.org/agrissearch/search.do? recordID=QV8900046

Pierre J, Le Guen J, MH Pham Delègue, J Mesquida, R Marilleau, G Morin (1996) Comparative study of nectar secretion and attractivity to bees of two lines of springtype faba bean (Vicia faba L var equine Steudel). Apidologie 27:65-75.

Pinheiro J, Bates D, DebRoy S, Sarkar D, R Core Team (2021) nlme: Linear and Nonlinear Mixed Effects Models. R package version 3.1-152, https:/CRAN.Rproject.org/package=nlme

Poulsen MH (1973) The frequency and foraging behaviour of honeybees and bumble bees on field beans in Denmark. Journal of Apicultural Research 12: 75-80.

R Core Team (2019) R: a language and environment for statistical computing. R Foundation for Statistical Computing. Vienna, Austria.

Ramires E (2019) Preferencias florales, cambios poblacionales y distribución del abejorro Bombus dahlbomii en Valdivia Thesis. Austral Universidad de Chile, Valdivia, Chile.

Saéz A, Morales CL, L Garibaldi, Aizen M, (2017) Invasive bumble bees reduce nectar availability for honey bees by robbing raspberry flower buds. Basic and Applied Ecology 19: 26-35.

Sáez A, Morales CL, Ramos LY, Aizen MA (2014) Extremely frequent bee visits increase pollen deposition but reduce drupelet set in raspberry. Journal of Applied Ecology 51: 1603-1612.

Scriven WA, Cooper BA, Allen H (1961) Pollination of field beans. Outlook on Agriculture 3: 69-75.

Singh AK, Bharati RC, Manibhushan NC, Pedpati A (2013) An assessment of faba bean (Vicia faba L.) current status and future prospect. African Journal of Agricultural Research 8: 6634-6641.

Smith-Ramírez C, Ramos-Jiliberto R, Valdovinos FS, Martínez P, Castillo JA, Armesto JJ (2014) Decadal trends in the pollinator assemblage of Eucryphia cordifolia in Chilean rainforests. Oecologia 176: 157-169.

Smith-Ramírez C, Vieli L, Barahona-Segovia RM, Montalva J, Cianferoni F, Ruz L, Fontúrbel FE, Valdivia CE, Medel R, Pauchard A, Celis-Diez JL, Riesco V, Monzón V, Vivallo F, Neira M (2018) Las razones de por qué Chile debe detener la importación del abejorro comercial Bombus terrestris (Linnaeus) y comenzar a controlarlo. Gayana 82: 118-127.

Sommerville D (1999) Honeybees (Apis mellifera L.) increase yields of faba beans (Vicia faba L.) in New South Wales while maintaining adequate protein requirements from faba bean pollen. Animal Production Science 39: 1001-1005.

Stoddard FL (1986) Floral viability and pollen tube growth in Vicia faba L. Journal of Plant Physiology 12: 249-262.

Stoddard FL, Bond DA (1987) The pollination requirements of the faba bean. Bee World 68: 144-152.

Stpiczyńska M (1995) The structure of floral nectaries of some species of Vicia L. (Papilionaceae). Acta Societatis Botanicorum Poloniae 64: 327-334.

Suso MJ, Maalouf F (2010) Direct and correlated responses to upward and downward selection for outcrossing in Vicia faba. Field Crops Research 116: 116126.

Tasei JN (1976) Pollinators of winter beans Vicia-fabaequina and pollination of male sterile plants for hybrid seed production. Apidologie 7: 1-38.

Venables WN, Ripley BD (2002) Modern Applied Statistics with S, Fourth edition. Springer, New York. ISBN 0-387-95457-0, https://www.stats.ox.ac.uk/pub/ MASS4/.

Wagenmakers E J, Farrell S (2004). AIC model selection using Akaike weights. Psychonomic bulletin \& review, 11(1), 192-196. 